\title{
Intravenous Lidocaine does not Reduce Emergence Agitation or Pain after Sevoflurane Anesthesia in Children
}

\author{
Department of Anesthesiology and Pain Medicine, School of Medicine, Keimyung University, Daegu, Korea
}

Young Ho Jang, M.D, and Soo Ryung Oh, M.D.

Background: Sevoflurane has a higher incidence of emergence agitation (EA) in children. We examined the effect of IV lidocaine doing the incidence of EA and the severity of postoperative pain in children who received sevoflurane anesthesia

Methods: Eighty five children aged 2-7 years undergoing sevoflurane anesthesia were studied. Patients were randomly assigned to one of the two groups: Group C $(n=42)$ wherein subjects received saline solution, and Group L $(n=43)$ where they received $1.5 \mathrm{mg} / \mathrm{kg}$ of IV lidocaine 5 minutes before emergence from anesthesia. The recovery time, EA score, CHEOPS score and modified Aldrete postanesthesia score were repeatedly measured at the postanesthesia care unit (PACU).

Results: The time until first cough was significantly longer in group L. The EA score and CHEOPS score were not significantly different between the two groups. There was no significant difference in the use of additional analgesics or sedatives for treatment of severe EA or severe pain.

Conclusions: After sevoflurane anesthesia, $1.5 \mathrm{mg} / \mathrm{kg}$ of IV lidocaine 5 minutes before extubation did not reduce the incidence of EA and the severity of postoperative pain. The time to discharge from the PACU was similar to that with placebo. (Korean J Anesthesiol 2005; 49: S 14 9)

Key Words: agitation, emergence, lidocaine, pain, pediatrics, sevoflurane.

\section{INTRODUCTION}

Sevoflurane has been associated with a high incidence of emergence agitation (EA) in children. ${ }^{1,2)}$ The proposed causes of EA following sevoflurane anesthesia include rapid emergence, variable neurological activity, and increased pain sensation. ${ }^{3)} \mathrm{A}$ variety of pharmacological strategies, such as opioids (fentanyl or nalbuphine), ${ }^{4-8)}$ ketamine, ${ }^{9)}$ a2-agonists (clonidine or dexmedetomidine), ${ }^{10,11)}$ midazolam $^{12)}$ or regional analgesia ${ }^{13)}$ have been tried to reduce the incidence and severity of EA. Opioids are the most frequently used agents in this context largely due to their consistent and reliable results in the therapy for EA. ${ }^{4-7)}$ However, the routine use of fentanyl to prevent EA is still questionable because of the increase in postoperative nausea and vomiting (PONV) in up to $75 \%$ cases and the associated delay in recovery. ${ }^{6,7)}$ Nalbuphine, an

Received : May 27, 2005

Corresponding to : Young Ho Jang, Department of Anesthesiology and Pain Medicine, School of Medicine, Keimyung University, 194 Dongsan-dong, Jung-gu, Daegu 700-712, Korea. Tel: 82-53-2507287, Fax: 82-53-250-7240, E-mail: weonjo@dsmc.or.kr agonist-antagonist opioid, may be an useful adjuvant to treat EA in children, ${ }^{8)}$ but since it acts as antagonist at the mu opioid receptor site, it can potentially reverse the analgesia obtained by the administration of a mu opioid agonist. Orally or intravenously administered ketamine reduced the incidence of EA in children ${ }^{9,14)}$ but results in nystagmus as well as an increased need for oxygen supplementation following extubation. ${ }^{9}$ Midazolam and other sedatives significantly prolong the duration of emergence when used to reduce the incidence of EA. Therefore, they can be safely used only after the pain has been adequately controlled. ${ }^{15)}$ Emergence from anesthesia and discharge time have been shown to be prolonged after premedication with midazolam in children receiving sevoflurane anesthesia. ${ }^{12)}$

Intravenous (IV) lidocaine suppresses neural excitability and reduces the neural response to postoperative pain by inhibition of nerve conduction. ${ }^{16,17)}$ It suppresses central sensitization and reduces postoperative pain in the clinical setting. ${ }^{18)}$ However, the beneficial effect of IV lidocaine on acute pain is still debatable. Despite these observations, prophylactic IV lidocaine given pre-extubation is well known to attenuate patient response to tracheal extubation. ${ }^{19)}$ IV lidocaine 5 minutes prior to extubation 
had a significant elevation of sedation score in the early postoperative period after tosillectomy and adenoidectomy. ${ }^{20)}$

The purpose of the present study was to investigate the effect of IV lidocaine on the incidence of EA and postoperative pain following sevoflurane anesthesia in children.

\section{MATERIALS AND METHODS}

This study was a randomized, double blind, single-dose trial. After obtaining approval from the Clinical Investigation Committee and written informed parental consent, 2-7 year-old pediatric patients scheduled to have superficial lower abdominal and genital surgery were enrolled. All patients were ASA physical status I or II and were scheduled to receive general anesthesia with sevoflurane. Children who had an experience of previous general anesthetic and children with central nervous system, hepatic or renal dysfunction, sleep apnea, developmental delay, or preceding psychological or psychiatric disorders were excluded from the study. Patients fasted for 4-6 hours prior to surgery as a part of the standard pre-anesthetic protocol in our institute. No sedative premedication was administered prior to the induction of anesthesia.

One of parents stayed with the child in the operating room (OR) during the induction of anesthesia. Standard monitoring was performed throughout the stay in the OR, including electrocardiography (ECG), pulse oximetry $\left(\mathrm{SpO}_{2}\right)$, noninvasive blood pressure (NIBP), and temperature. End-tidal concentrations of carbon dioxide $\left(\mathrm{ETCO}_{2}\right)$ and sevoflurane were measured continuously using infrared anesthetic gas analyzer (Capnomac, Datex-Ohmeda, Finland). Ondansetron was administered at 0.1 $\mathrm{mg} / \mathrm{kg}$ (maximum $4 \mathrm{mg}$ ) to reduce the incidence of PONV. Anesthesia was administered by the same anesthesiologist for all the procedures included this study. All investigators evaluating the children during the intra- and postoperative period were blinded to each group.

Pre-induction distress of the patients was measured by the participating anesthesiologist and rated on a four-point score $(1=$ calm and cooperative, $2=$ mildly anxious but consolable, $3=$ tearful and inconsolable, 4 = totally out of control) proposed by Keaney et al. $^{21)}$ All patients received $100 \%$ oxygen prior to anesthetic induction using an alternative supplemental oxygen source and a face mask. Following preoxygenation, patients took tidal or vital capacity breath using a face mask with primed circuit, with 8 vol\% dialed sevoflurane (Vaporizer 2000, Drager, Wisconsin, USA) in a mixture of $75 \%$ nitrous oxide in oxygen at 4
L/min fresh gas flow. Cricoid pressure was applied following loss of consciousness and eyelash reflex. Assisted ventilation with a face mask was gradually switched to standard controlled ventilation. IV access was established and an infusion of $\mathrm{D}_{5} 1 / 3 \mathrm{NS}$ was started, as per our institute's standard practice. Nitrous oxide was discontinued 1 minute following satisfactory inhalation induction and the vaporizer was set to $3 \%$ sevoflurane in $100 \%$ oxygen at $4 \mathrm{~L} / \mathrm{min}$ for endotracheal intubation. The sevoflurane concentration was adjusted according to patient's vital signs with nitrous oxide $50 \%$ in oxygen. Ventilation was assisted to attain $\mathrm{ETCO}_{2}$ between $35-40 \mathrm{mmHg}$ during the procedure. No analgesics or local anesthetics other than study drug were administered during surgery, except $0.1 \mathrm{mg} / \mathrm{kg}$ of IV ondansetron as part of anesthetic regimen.

Patients were randomly assigned to one of the two groups (Group C; Control vs. Group L; IV Lidocaine). To protect the double blind design of the study, all study drugs and placebos were prepared and labeled with only the patients' name and hospital number by one OR nurse who did not participate in the process of evaluation of study groups. Patients in Group L received 1.5 $\mathrm{mg} / \mathrm{kg}$ IV lidocaine over $30-45$ seconds 5 minutes before discontinuation of their anesthetic by the blinded anesthesiologist. Group C patients received an equal volume of IV saline.

At the conclusion of the operative procedure, sevoflurane and nitrous oxide were simultaneously discontinued. Spontaneous respiration was permitted following the return of the cough reflex. Patients were extubated and transferred to the postanesthesia care unit (PACU) once they demonstrated a regular respiratory pattern, facial grimacing, gag reflex and purposeful movements. The time until first cough, facial grimacing, eye opening and time to extubation following discontinuation of sevoflurane and nitrous oxide were documented.

One trained anesthesiologist, blinded to patient group assignment, was present upon admission to the PACU. The ECG, NIBP and $\mathrm{SpO}_{2}$ monitoring were measured throughout the stay in PACU. A parent was allowed to be at the child's bedside immediately upon admission to the PACU. Adverse events including hypotension, seizure, deep sedation, arrhythmia, and PONV were recorded during the recovery period.

Postoperative pain was assessed using the CHEOPS (Children's Hospital of Eastern Ontario Pain Scale) scores based on crying, facial expression, verbal statements, position of torso, touching of the wound, and movement of legs. ${ }^{22)}$ EA score was evaluated by using five-point scores $(1=$ obtunded patient with no response to stimulation, 2 = asleep but responsive to movement or stimulation, 
3 = awake and appropriately responsive, $4=$ crying and difficult to console, $5=$ wild thrashing behavior that requires restraint) by Cravero et al. ${ }^{2)}$ A EA score $\geq 4$ or CHEOPS score $\geq 9$ despite all calming efforts by the child's parents or guardians and nursing personnel were considered as severe EA or severe pain, respectively. IV ketolorac tromethamine $(0.5 \mathrm{mg} / \mathrm{kg})$ was administered in such situations. Fentanyl $(1 \mathrm{Hg} / \mathrm{kg})$ was administered if severe EA or severe pain persisted even after IV ketorolac tromethanine administration.

A score of $\geq 8$ on the modified Aldrete postanesthesia score was used as the criterion for transferring subjects from PACU to ward. ${ }^{9)}$ The EA score, CHEOPS score and modified Aldrete postanesthesia score were serially documented for 20 minutes with the 5 minute interval upon arrival in the PACU. Then the children were allowed to transfer from PACU to the ward after confirmation of the modified Aldrete postanesthesia score $\geq 8$ points. The time to modified Aldrete postanesthesia score $\geq 8$ and the time to discharge from the PACU were recorded.

Analyses were performed using the SPSS statistical Package program version 11.0 (SPSS for windows, SPSS Inc., Chicago, IL, USA). Data are expressed as means \pm SD. Sample size calculation was performed by considering the $30 \%$ incidence of severe EA based on the report by Beskow and Westrin. ${ }^{15)}$ With power of $80 \%$ and type 1 error of $5 \%$, we calculated that 39 subjects were required per group. Data were analysed using Student's $t$-test and Kruskal-Wallis tests when comparing the demographic data. Nonparametric data including sex, EA score, CHEOPS score, and modified Aldrete score were compared by using $x^{2}$ analysis and Fisher's exact test. P-values $<0.05$ were considered statistically significant.

Table 1. Demographic Data and Preoperative Distress Scale

\begin{tabular}{lcc} 
& $\begin{array}{l}\text { Group C } \\
(\mathrm{n}=42)\end{array}$ & $\begin{array}{l}\text { Group L } \\
(\mathrm{n}=43)\end{array}$ \\
\hline Age $(\mathrm{yr})$ & $4.6 \pm 2.0$ & $4.3 \pm 1.7$ \\
Sex $(\mathrm{M} / \mathrm{F})$ & $21 / 21$ & $23 / 20$ \\
Body weight $(\mathrm{kg})$ & $19.3 \pm 7.0$ & $18.1 \pm 4.4$ \\
Duration of anesthesia (min) & $61.7 \pm 25.3$ & $62.4 \pm 26.1$ \\
Preoperative distress scale & $1.8 \pm 0.9$ & $1.9 \pm 1.0$ \\
\hline
\end{tabular}

Values are mean \pm SD. Group C: control, Group L: $1.5 \mathrm{mg} / \mathrm{kg}$ of IV lidocaine 5 minutes before extubation. Preoperative distress scale: $1=$ calm and cooperative, $2=$ mildly anxious but consolable, $3=$ tearful and inconsolable, $4=$ totally out of control. No significant difference between two groups.

\section{RESULTS}

The groups were similar in respect to age, gender, weight and anesthetic duration (Table 1). Preoperative distress scores in children were $1.8 \pm 0.9$ in group $\mathrm{C}$ and $1.9 \pm 1.0$ in group $\mathrm{L}$, respectively $(\mathrm{P}>0.05)$. None of the patients in either group experienced any episodes of hypoxia, hypotension, seizure, deep sedation, arrhythmia or PONV requiring treatment during their postoperative stay in the PACU.

There were no significant differences during recovery with respect to the time to facial grimacing, eye opening and extubation after discontinuation of sevoflurane and nitrous oxide between the two groups, although the time until first cough was significantly longer in group L (Table 2).

The five-point EA score and CHEOPS score on arrival at PACU were not significantly different between the two groups. There was no significant difference in the time to modified Aldrete

Table 2. Emergence Characteristics

\begin{tabular}{lcc} 
& $\begin{array}{l}\text { Group C } \\
(\mathrm{n}=42)\end{array}$ & $\begin{array}{l}\text { Group L } \\
(\mathrm{n}=43)\end{array}$ \\
\hline Time to first cough (min) & $6.6 \pm 3.8$ & $8.9 \pm 6.3^{*}$ \\
Time to facial grimacing (min) & $9.5 \pm 6.8$ & $10.1 \pm 8.4$ \\
Time to eye opening (min) & $16.4 \pm 9.8$ & $19.8 \pm 10.8$ \\
Time to extubation (min) & $7.7 \pm 3.8$ & $8.7 \pm 3.5$
\end{tabular}

Values are mean \pm SD. Group C: control, Group L: $1.5 \mathrm{mg} / \mathrm{kg}$ of IV lidocaine 5 minutes before extubation. ${ }^{*} \mathrm{P}<0.05$ vs. group C.

Table 3. Progress during Stay at Postanesthesia Care Unit

\begin{tabular}{lcc} 
& $\begin{array}{l}\text { Group C } \\
(\mathrm{n}=42)\end{array}$ & $\begin{array}{l}\text { Group L } \\
(\mathrm{n}=43)\end{array}$ \\
\hline $\begin{array}{l}\text { EA score on arrival at PACU } \\
\text { CHEOPS score on arrival }\end{array}$ & $2.6 \pm 1.3$ & $2.3 \pm 1.5$ \\
$\quad 7.7 \pm 2.2$ & $7.4 \pm 2.0$ \\
$\quad \begin{array}{l}\text { Time PACU } \\
\quad \text { score modified Aldrete }\end{array}$ & $6.2 \pm 8.0$ & $8.1 \pm 10.1$ \\
$\begin{array}{l}\text { Time to discharge from PACU } \\
\text { (min) }\end{array}$ & $21.4 \pm 10.0$ & $21.5 \pm 8.9$ \\
\end{tabular}

Values are mean \pm SD. Group C: control, Group L: $1.5 \mathrm{mg} / \mathrm{kg}$ of IV lidocaine 5 minutes before extubation. EA: emergence agitation, PACU: postanesthesia care unit, CHEOPS: Children's Hospital of Eastern Ontario Pain Scale. Modified Aldrete score and agitation score: see the text. 


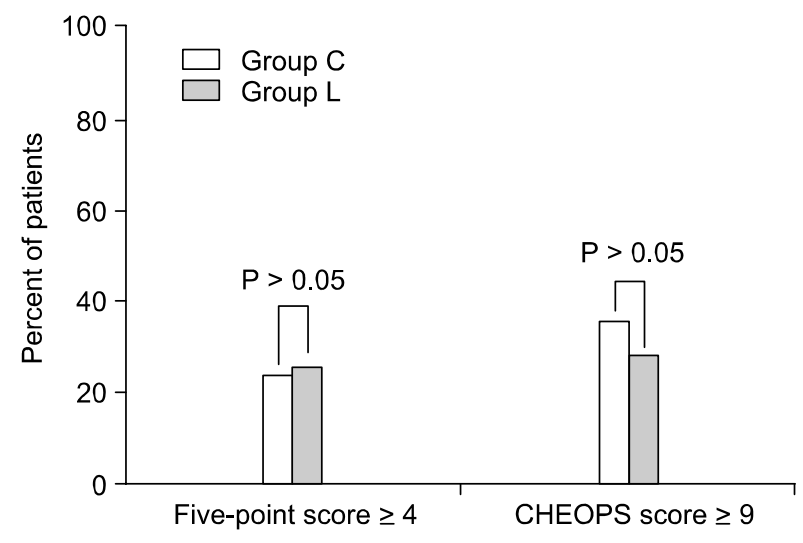

Fig. 1. Accumulated incidence of emergence agitation (five-point score $\geq 4$ ) and severe pain (CHEOPS score $\geq 9$ ) after sevoflurane anesthesia in children. Group C: control, Group L: $1.5 \mathrm{mg} / \mathrm{kg}$ of IV lidocaine 5 minutes before extubation. CHEOPS: Children's Hospital of Eastern Ontario Pain Scale. CHEOPS score and five-point score: see the text.

postanesthesia score $\geq 8$ and the time to discharge from the PACU between the two groups (Table 3).

Ten children $(23.8 \%)$ in group $\mathrm{C}$ and $11(25.6 \%)$ in group L experienced severe EA (five-point EA score $\geq 4$ ) (Fig. 1). Fifteen children (35.7\%) of group $\mathrm{C}$ and $12(27.9 \%)$ of group L experienced severe pain (CHEOPS score $\geq 9$ ). There were no significant differences in the incidence of severe EA or severe pain between the two groups.

Sixteen (38.1\%) patients in group C and 15 (34.9\%) patients in group $\mathrm{L}$ received IV ketorolac tromethanine for severe EA and/or severe pain $(\mathrm{P}>0.05)$. Eight $(19.0 \%)$ patients in group $\mathrm{C}$ and $8(18.6 \%)$ patients in group L received additional IV fentanyl because the EA and/or CHEOPS scores were not reduced to below moderate following the administration of IV ketorolac tromethanine (Fig. 2).

\section{DISCUSSION}

Postoperative IV lidocaine is known to reduce the incidence of postoperative cough and improve postoperative outcome. ${ }^{24)} \mathrm{A}$ thorough literature search did not reveal any previous investigations looking at the effect of IV lidocaine on EA following sevoflurane anesthesia in children. The present study was designed to investigate the effects of single-bolus placebo and IV lidocaine on the incidence and severity of EA and recovery from anesthesia.

The reported incidence of EA in children after sevoflurane anesthesia varies from 10 to $80 \%{ }^{1,2)}$ Various factors, such as

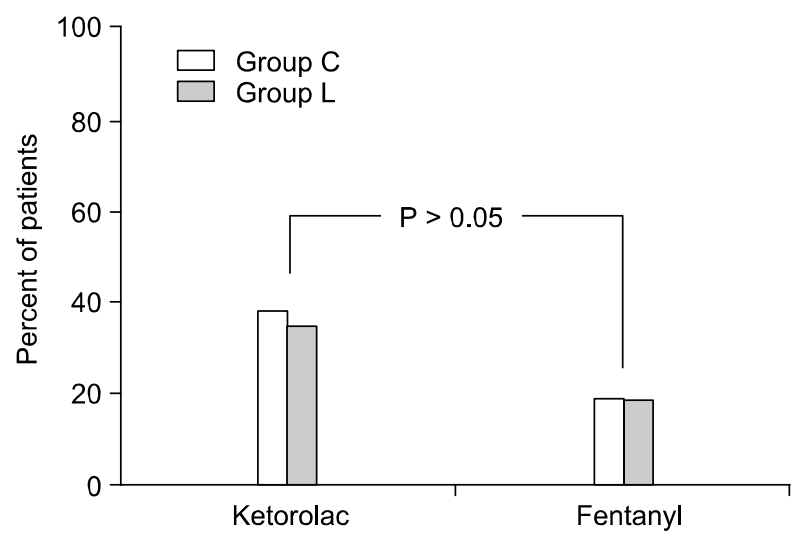

Fig. 2. Frequency of intravenous ketorolac tromethanine and/or fentanyl administration. Group C: control, Group L: $1.5 \mathrm{mg} / \mathrm{kg}$ of IV lidocaine 5 minutes before extubation. Ketorolac tromethanine is administered for the treatment of emergence agitation (scale $\geq 4$ ) or severe pain (CHEOPS $\geq 9$ ). Fentanyl is administered for persisted emergence agitation or severe pain following ketorolac tromethanine administration.

opioid administration, premedication, postoperative pain, patient's age, scoring system or preoperative anxiety are associated with the incidence of EA after anesthesia. ${ }^{3,4,6,9,15,25)}$ The incidences of severe EA in our study were $23.8 \%$ in control group and $25.6 \%$ in lidocaine group, respectively, which are similar to an earlier report by Beskow and Westrin. ${ }^{15)}$ Unexpectedly, the administration of IV lidocaine $1.5 \mathrm{mg} / \mathrm{kg} 5$ minutes before discontinuation of sevoflurane did not reduce the incidence of EA in children in this study protocol.

Repeated assessments of EA following anesthetic recovery are essential to define the incidence and duration of EA. We limited our observations to EA and CHEOPS scores for only 20 min with 5 minute interval upon arrival in the PACU due to a busy PACU circumstances and a rapid turnover surgical setting. However, the highest incidence of EA occurs within the first 10 minutes and progressively decreases with increasing time following anesthesia. ${ }^{23)}$ Therefore, we think that our observational period of 20 minutes may be sufficient to reflect the total incidence of EA and pain at PACU.

Sevoflurane and desflurane are volatile agents with low blood and tissue solubilities. Thus, they are associated with a high incidence of EA in children. ${ }^{1,24)}$ There are numerous adverse effects of EA, including a risk of self-injury, bleeding, and inadvertent removal of drains and intravenous catheters. ${ }^{26,27)}$ EA may complicate postanesthetic care and delay discharge from PACU. ${ }^{1,26)}$ Consequently, children who experience EA generally 
require the administration of additional analgesics or sedatives, as well as additional nursing care. EA may be the result of a rapid washout of sevoflurane, thereby resulting in sub-anesthetic concentrations that do not provide analgesia. Adequate postoperative analgesia appears to be necessary to minimize the incidence of excitatory effects. This was demonstrated in an analysis that found the incidence of EA among subjects receiving sevoflurane to be significantly higher in patients undergoing inguinal hernia repair when they did not receive caudal anesthesia for adequate pain relief. ${ }^{13)}$ Differentiating between EA and pain in children during immediate postoperative period is extremely difficult and may sometimes be impossible. Most of our patients who received additional analgesics (IV ketorolac tromethanine with or without additional fentanyl) had both severe EA and severe pain. There were no significant differences in the use of IV ketorolac tromethanine and fentanyl with or without administration of IV lidocaine. In other words, $1.5 \mathrm{mg}$ of IV lidocaine did not reduce the incidence of severe EA and pain following emergence from sevoflurane anesthesia.

We did not measure lidocaine blood concentrations in this study. Lidocaine blood levels peak at the first minute after an IV bolus (28). Koc et al. $^{20)}$ demonstrated that IV lidocaine $1 \mathrm{mg} / \mathrm{kg} 5$ minutes prior to extubation had a higher sedation score at five minutes postoperatively. This was the reason for administration of IV lidocaine 5 minutes before emergence from anesthesia in this study.

IV lidocaine acts as a central nervous system depressant and has a sedative effect. ${ }^{29)}$ Therefore, it increases the depth of general anesthesia. In our study, the time to modified Aldrete score, CHEOPS score and the time to discharge from the PACU were not significantly different between the two groups. As a result, we did not observe any sedative effect in our patients following 1.5 $\mathrm{mg} / \mathrm{kg}$ IV lidocaine after sevoflurane anesthesia.

In conclusion, $1.5 \mathrm{mg}$ of IV lidocaine 5 minutes before extubation at the end of surgery prolonged the time until first cough after sevoflurane anesthesia in children. The incidence of EA, severity of postoperative pain and the time to discharge from the PACU were not significantly different when compared to the placebo. Further studies on EA are indicated to determine if this treatment is warranted.

\section{REFERENCES}

1. Welborn LG, Hannallah RS, Norden JM, Ruttimann UE, Callan $\mathrm{C}$ : Comparison of emergence and recovery characteristics of sevoflurane, desflurane, and halothane in pediatric ambulatory patients. Anesth Analg 1996; 83: 917-20.

2. Cravero J, Surgenor S, Whalen K: Emergence agitation in paediatric patients after sevoflurane anaesthesia and no surgery: a comparison with halothane. Paediatr Anaesth 2000; 10: 419-24.

3. Cohen IT, Finkel JC, Hannallah RS, Hummer KA, Patel KM: The effect of fentanyl on the emergence characteristics after desflurane or sevoflurane anesthesia in children. Anesth Analg 2002; 94: 1178-81.

4. Cohen IT, Hannallah RS, Hummer KA: The incidence of emergence agitation associated with desflurane anesthesia in children is reduced by fentanyl. Anesth Analg 2001; 93: 88-91.

5. Finkel JC, Cohen IT, Hannallah RS, Patel KM, Kim MS, Hummer $\mathrm{KA}$, et al: The effect of intranasal fentanyl on the emergence characteristics after sevoflurane anesthesia in children undergoing surgery for bilateral myringotomy tube placement. Anesth Analg 2001; 92: 1164-8.

6. Binstock W, Rubin R, Bachman C, Kahana M, McDade W, Lynch JP: The effect of premedication with OTFC, with or without ondansetron, on postoperative agitation, and nausea and vomiting in pediatric ambulatory patients. Paediatr Anaesth 2004; 14: 759-67.

7. Demirbilek S, Togal T, Cicek M, Aslan U, Sizanli E, Ersoy MO: Effects of fentanyl on the incidence of emergence agitation in children receiving desflurane or sevoflurane. Eur J Anaesthesiol 2004; 21: $538-42$.

8. Picard V, Dumont L, Pellegrini M: Quality of recovery in children: sevoflurane versus propofol. Acta Anaesthesiol Scand 2000; 44: 307-10.

9. Kararmaz A, Kaya S, Turhanoglu S, Ozyilmaz MA: Oral ketamine premedication can prevent emergence agitation in children after desflurane anaesthesia. Paediatr Anaesth 2004; 14: 477-82.

10. Kulka PJ, Bressem M, Tryba M: Clonidine prevents sevofluraneinduced agitation in children. Anesth Analg 2001; 93: 335-8.

11. Ibacache ME, Munoz HR, Brandes V, Morales AL: Single-dose dexmedetomidine reduces agitation after sevoflurane anesthesia in children. Anesth Analg 2004; 98: 60-3.

12. Viitanen H, Annilla P, Viitanen M, Tarkkila P: Premedication with midazolam delays recovery after ambulatory sevoflurane anesthesia in children. Anesth Analg 1999; 89: 75-9.

13. Aouad MT, Kanazi GE, Siddik-Sayyid SM, Gerges FJ, Rizk LB, Baraka AS: Preoperative caudal block prevents emergence agitation in children following sevoflurane anesthesia. Acta Anaesthesiol Scand 2005; 49: 300-4.

14. Kawaraguchi Y, Miyamoto Y, Fukumitsu K, Taniguchi A, Hirao $\mathrm{O}$, Kitamura $\mathrm{S}$, et al: The effect of ketamine on reducing postoperative agitation after sevoflurane anesthesia in pediatric strabismus surgery. Masui 2002; 51: 1343-8.

15. Beskow A, Westrin P: Sevoflurane causes more postoperative agitation in children than does halothane. Acta Anaesthesiol Scand 1999; 43: 536-41.

16. Groudine SB, Fisher HA, Kaufman RP Jr, Patel MK, Wilkins LJ, Mehta SA, et al: Intravenous lidocaine speeds the return of bowel 
function, decreases postoperative pain, and shortens hospital stay in patients undergoing radical retropubic prostatectomy. Anesth Analg 1998; 86: 235-9.

17. Dirks J, Fabricius P, Petersen KL, Rowbotham MC, Dahl JB: The effect of systemic lidocaine on pain and secondary hyperalgesia associated with the heat/capsaicin sensitization model in healthy volunteers. Anesth Analg 2000; 91: 967-72.

18. Kawamata M, Takahashi T, Kozuka Y, Nawa Y, Nishikawa K, Narimatsu E, et al: Experimental incision-induced pain in human skin: effects of systemic lidocaine on flare formation and hyperalgesia. Pain 2002; 100: 77-89.

19. Mikawa K, Nishina K, Takao Y, Shiga M, Maekawa N, Obara $\mathrm{H}$ : Attenuation of cardiovascular responses to tracheal extubation: comparison of verapamil, lidocaine, and verapamil-lidocaine combination. Anesth Analg 1997; 85: 1005-10.

20. Koc C, Kocaman F, Aygenc E, Ozdem C, Cekic A: The use of preoperative lidocaine to prevent stridor and laryngospasm after tonsillectomy and adenoidectomy. Otolaryngol Head Neck Surg 1998; 118: 880-2.

21. Keaney A, Diviney D, Harte S, Lyons B: Postoperative behavioral changes following anesthesia with sevoflurane. Paediatr Anaesth 2004; 14: 866-70.

22. Bennie RE, Boehringer LA, Dierdorf SF, Hanna MP, Means LJ: Transnasal butorphanol is effective for postoperative pain relief in children undergoing myringotomy. Anesthesiology 1998; 89:
385-90.

23. Cole JW, Murray DJ, McAllister JD, Hirshberg GE: Emergence behavior in children: defining the incidence of excitement and agitation following anaesthesia. Paediatr Anaesth 2002; 12: 442-7.

24. Tam S, Chung F, Campbell M: Intravenous lidocaine: optimal time of injection before tracheal intubation. Anesth Analg 1987; 66: 1036-8.

25. Aono J, Mamiya K, Manabe M: Preoperative anxiety is associated with a high incidence of problematic behavior on emergence after halothane anesthesia in boys. Acta Anaesthesiol Scand 1999; 43: 542-4.

26. Voepel-Lewis T, Malvuya S, Tait AR: A prospective cohort study of emergence agitation in the pediatric postanesthesia care unit. Anesth Analg 2003; 96: 1625-30.

27. Uezono S, Goto T, Terui K, Ichinose F, Ishguro Y, Nakata Y, et al: Emergence agitation after sevoflurane versus propofol in pediatric patients. Anesth Analg 2000; 91: 563-6.

28. Patel RI, Peterson RG, Aldrete JA: Endotracheal compared with intravenous injection of $3 \mathrm{mg} / \mathrm{kg}$ of lignocaine. Measurement of arterial and venous levels. Anaesthesia 1981; 36: 772-4.

29. Nishino T, Hiraga K, Sugimori K: Effects of i.v. lignocaine on airway reflexes elicited by irritation of the tracheal mucosa in humans anaesthetized with enflurane. Br J Anaesth 1990; 64: 682-7. 